\title{
MODELLING OF COLLISIONS OF THE AUTOMOBILES
}

\author{
Edgar Sokolovskij ${ }^{1}, \check{S}$ arūnas Mikaliūnas ${ }^{2}$ \\ ${ }^{1}$ Dept of Transport Technological Equipment, Vilnius Gediminas Technical University, \\ Plytinès g. 27, LT-10105 Vilnius, Lithuania.E-mail: Edgar.Sokolovskij@ti.vtu.lt \\ ${ }^{2}$ Dept of Railway Transport, Vilnius Gediminas Technical University, J. Basanavičiaus g. 28, \\ LT-03224Vilnius, Lithuania.E-mail: Sarunas.Mikaliunas@ti.vtu.lt
}

Received 20 April 2006; accepted 4 September 2006

\begin{abstract}
The graphic analytical modelling and the computer modelling of collisions of the automobiles are compared in this article. The examples of modelling of collisions of the automobiles are given. The computer modelling of collision of the automobiles with the help of the program PC CRASH is introduced. The possibilities and advantages of this computer program, the inserted parameters and their optimization are investigated. The possibilities of applying the computer modelling program in the experts' examination of traffic accidents while modelling collisions of the automobiles, the items and requirements raised towards the experts, who work with such programs, on reliability of the obtained results are considered.
\end{abstract}

Keywords: automobile, collision, computer modelling, traffic accident, examination.

\section{Introduction}

The graphic analytical modelling of movement and collision of vehicles requires many efforts and much time [1-4], especially wishing to consider several possible variants. The computer modelling, which implies application of special computer programs meant for this purpose, makes the task easier.

The program PC CRASH is one of the computer programs meant for modelling of vehicles, which also enables to model collisions of the automobiles [5, 6]. As in case of the graphic analytical modelling, while carrying out the computer modelling, much depends upon the selected (inserted) parameters [1-4, 7-10]. The more precise the inserted parameters are, the more precise result of the computer modelling will be.

\section{Graphic analytical modelling of collision of the automobiles}

It is a usual case, when, while investigating the circumstances of the traffic accident, firstly the scale plan of the place of accident is drawn, the place of collision is fixed, the position of the automobiles at the moment of collision is ascertained according to the external damages caused to the automobiles, and calculations are made. Seeking to ascertain the speed of movement of the automobiles prior to the traffic accident, it is necessary to ascertain the speed of movement of the automobiles after the occurred collision, to evaluate expenditures of the automobile's energy at the moment of its sliding, rotating around its own vertical symmetry axis and turning over after the occurred collision. Thus, after having evaluated the quantities of the automobiles' energy, which was lost at the moment of collision and braking prior to the collision, the speed of movement of the automobiles prior to the traffic accident are ascertained. The speed of movement of the automobiles prior to the occurred collision is ascertained according to their speed after the occurred collision by applying the law of conservation of the movement quantity [1-3]:

$$
\overline{m_{1} V_{1}}+\overline{m_{2} V_{2}}=\overline{m_{1} V_{1}^{\prime}}+\overline{m_{2} V_{2}^{\prime}}=\text { const, }
$$

where $m_{1}, m_{2}$ is the automobiles' masses; $V_{1}, V_{2}$ is the speed of movement of the automobiles prior to the occurred collision; $V_{1}^{\prime}, V_{2}^{\prime}$ is the speed of movement of the automobiles after the occurred collision.

The scheme for calculation is used for this purpose. The vectors of the quantity of the automobiles' movement in the system of coordinates are moved to the beginning of the system of coordinates; thus, all the vectors of the movement quantity (their directions coincide with the directions of the vectors of the appropriate speed) are projected on the axes of coordinates. Two equations, containing two unknown values, i.e. the speed of the automobiles prior to the occurred collision, are obtained. While calculating, it is more convenient to project all the vectors 
of the movement quantity on the axes, which are perpendicular to the direction of movement of each automobile prior to the occurred collision. Thus, the projection of the vector of the quantity of movement of one automobile prior to the occurred collision in each equation will be equal to a "zero" and it is possible to calculate at once the speed of another automobile prior to the occurred collision.

As an example, let us investigate the definite case of the traffic accident, in the course of which two automobiles collided. The situation at the place of the occurred traffic accident is reflected in Fig 1.

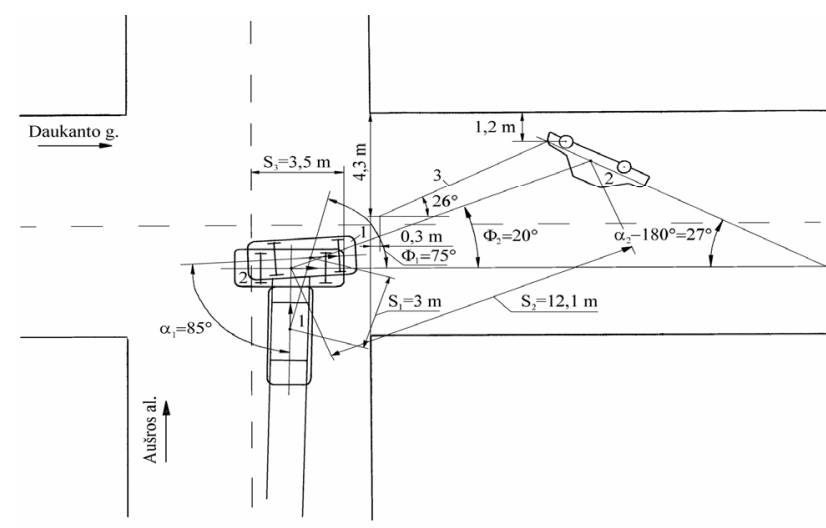

Fig 1. The plan of the place of automobiles collision: 1,2 are the automobiles; 3 is the mark of sliding of the 2 nd automobile

The speed of movement of the 1st automobile after the occurred collision $(\mathrm{km} / \mathrm{h})[1,3]$ :

$$
V_{1}^{\prime}=3,6 \cdot \sqrt{2 g \varphi_{y 1} \cdot\left(S_{1}+2 a_{1} b_{1} \varepsilon_{1} / L_{1}\right)},
$$

where $g$ is the acceleration of gravity $\left(9,81 \mathrm{~m} / \mathrm{s}^{2}\right) ; \varphi_{y 1}$ is the coefficient of cohesion of the wheels of the 1st automobile while sliding in certain conditions of the road; $S_{1}$ is the distance, to which the centre of gravity of the 1st automobile has shifted after the occurred collision (Fig 1), $\mathrm{m} ; a_{1}$ is the distance from the centre of gravity of the 1st automobile to the front axis of the automobile, $\mathrm{m} ; b_{1}$ is the distance from the centre of gravity of the 1st automobile to the back axis of the automobile, $\mathrm{m} ; \varepsilon_{1}$ is the angle, at which the $1 \mathrm{st}$ automobile has turned after the occurred collision, rad; $L_{1}$ is the wheelbase of the 1 st automobile, $\mathrm{m}$.

The speed of movement of the 2nd automobile after the occurred collision $(\mathrm{km} / \mathrm{h})$ :

$$
\begin{aligned}
& V_{2}^{\prime}=\sqrt{\frac{26}{m_{2}}\left(A_{1}+A_{2}+A_{3}\right)} ; \\
& A_{1}=m_{2} g\left(\sqrt{\left(\frac{B}{2}\right)^{2}+h^{2}}-h\right) ; \\
& A_{2}=m_{2} g \varphi_{2}^{\prime} L_{2} \frac{\pi \alpha_{2}}{360} ;
\end{aligned}
$$

$$
A_{3}=m_{2} g \varphi_{2}^{\prime} S_{2},
$$

where $A_{1}$ is loss of the kinetic energy at the moment of turning of the 2nd automobile over, $\mathrm{J} ; A_{2}$ is loss of the kinetic energy at the moment of rotation of the 2nd automobile around its centre of gravity, $\mathrm{J} ; A_{3}$ is loss of the kinetic energy at the moment of shifting of the 2nd automobile to the position after the occurred collision, $\mathbf{J} ; m_{2}$ is the total mass of the 2 nd automobile together with the driver and the passengers, $\mathrm{kg} ; B$ is the width of the track of the 2 nd automobile, $\mathrm{m} ; h$ is the height of the centre of gravity of the loaded 2nd automobile (together with the passengers), $m ; \varphi_{2}$ is the coefficient of cohesion of the wheels of the 2 nd automobile while sliding in certain conditions of the road; $L_{2}$ is the wheelbase of the 2nd automobile, $\mathrm{m} ; \alpha_{2}$ is the angle, at which the 2nd automobile has turned after the occurred collision, deg.; $S_{2}$ is the distance, to which the centre of gravity of the 2 nd automobile has shifted after the occurred collision (Fig 1), $\mathrm{m}$.

Afterwards the speed of the automobiles at the moment of impact, i.e. just before collision, is ascertained. We are drawing the system of coordinates, making the vectors of the speed of movement of the automobiles prior and after the collision (Fig 2).

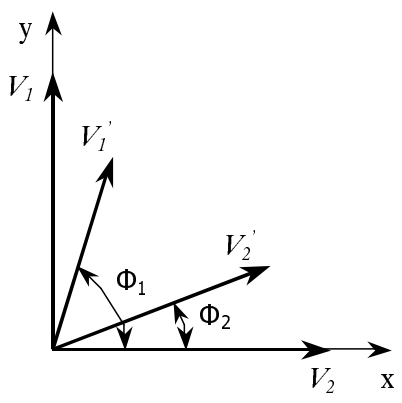

Fig 2. The vectors scheme, meant for calculation of the speed of movement of the automobiles prior to their collision

While projecting the vectors of the movement quantity on the axis $\mathbf{y}$, we get the speed of movement of the 1st automobile at the moment of impact:

$$
\begin{aligned}
& m_{1} V_{1}=m_{1} V_{1}^{\prime} \sin \Phi_{1}+m_{2} V_{2}^{\prime} \sin \Phi_{2} ; \\
& V_{1}=V_{1}^{\prime} \sin \Phi_{1}+\frac{m_{2}}{m_{1}} V_{2}^{\prime} \sin \Phi_{2},
\end{aligned}
$$

where $\Phi_{1}$ is the angle, at which the centre of gravity of the 1st automobile has shifted after the collision (Figs 1,2), deg.; $\Phi_{2}$ is the angle, at which the centre of gravity of the 2nd automobile has shifted after the collision (Figs 1, 2), deg.; $m_{1}$ is the total mass of the 1st automobile together with the driver and the passengers, kg.

While projecting the vectors on the axis $\mathbf{x}$, we get the speed of movement of the 2nd automobile at 
the moment of impact as well as its speed just before traffic accident (as the 2nd automobile was not braked prior to the collision):

$$
\begin{aligned}
& m_{2} V_{2}=m_{1} V_{1}^{\prime} \cos \Phi_{1}+m_{2} V_{2}^{\prime} \cos \Phi_{2} ; \\
& V_{a 2}=V_{2}=\frac{m_{1}}{m_{2}} V_{1}^{\prime} \cos \Phi_{1}+V_{2}^{\prime} \cos \Phi_{2} .
\end{aligned}
$$

As the 1st automobile was braked prior to the collision and left the wheels' braking traces, the speed of movement of the 1st automobile prior to being braked in the place of the traffic accident was:

$$
V_{a 1}=1,8 \cdot t_{3} \cdot j_{1}+\sqrt{26 \cdot S_{s t .} \cdot j_{1}+V_{1}^{2}},
$$

where $t_{3}$ is the time of increase of deceleration, $\mathrm{s} ; j_{1}$ is the maximal settled deceleration of the 1st automobile in certain road conditions, $\mathrm{m} / \mathrm{s}^{2} ; S_{\text {st. }}$ is the length of the braking trace of the 1st automobile right wheels', m.

It is obvious that much job is to be done, seeking to make this calculation, especially wishing to consider several possible variants (for example, in case of altering certain parameters).

\section{Computer modelling of collision of the automobiles}

The version 5.0 of the program PC CRASH was used for the computer modelling of collision of the automobiles $[5,6]$. While modelling with the help of this computer program, there is a possibility to choose and, while modelling, to evaluate the parameters of cohesion with the road surface as well as many other automobile's parameters such as the suspension parameters, the type of the tires, the extent of loading of the automobile, distribution of the braking forces, etc. There is a possibility to set various regimes of movement of the automobile (braking, acceleration), the parameters of deceleration and acceleration.

While carrying out the computer modelling of the accident (as in case with the graphic analytical modelling), usually the plan of the place of accident is drawn at first, the place of collision is fixed, the position of the automobiles at the moment of collision is ascertained according to the external damages, caused to the automobiles. Later on, while modelling, it is possible to alter the wished parameters (for example, positioning of the automobiles, the place of collision and the other parameters), seeking to investigate all possible variants. The parameters can be altered only with taking into consideration the existing objective data, i.e. only with taking into consideration the parameters, the precise values of which are unknown and are within the real limits.

Afterwards the movement of the automobiles or their collision are modelled in such a way, so that the movement of the automobiles resembles the traces and the other factors, which were fixed in the place of the accident, as much as possible. After having carried out the computer modelling, the automobiles should be located in the position, in which they were fixed after the traffic accident or as close to it as possible. It is possible to ascertain the speed of movement of the automobiles prior to the traffic accident by this method. The computer program PC CRASH provides the possibility to optimize the course of the accident according to certain chosen parameters. Thus, the program itself optimizes these chosen parameters to such an extent, so that the automobiles stop in the position, which is close to the position, in which they were fixed after the traffic accident. However, seeking to obtain as more precise result as possible, it is necessary to insert as many available parameters as possible, whereas the parameters, the values of which may fluctuate within the certain limit, should be optimized.

Fig 3 reflects the modelled collision of the automobiles LANCIA KAPPA and FORD SCORPIO. In this case it was necessary to ascertain, if the automobiles could occur in the fixed position with taking into consideration this particular nature of the collision, which is proved by the damages, caused to the automobiles, i.e. it was necessary to ascertain, if such traffic accident could really occur or it was forged.

The parameters of movement of the automobiles are inserted (Fig 4). The fact that the automobile FORD SCORPIO was slowing down with deceleration, equal to $2 \mathrm{~m} / \mathrm{s}^{2}$, after collision is introduced (Fig 5).

As it is known from the circumstances of the traffic accident that the driver of the automobile LANCIA KAPPA intended to turn to the left, turning of the automobile's front wheels is also inserted together with the other parameters of its movement after the occurred collision (Fig 6).

Both the parameters of movement of the automobile after the occurred collision and the parameters of collision are inserted (Fig 7); the impulse point and positioning of the planes of the occurred collision are selected. Besides, while modelling, many other parameters, such as the parameters of cohesion of the road surface, the profile of the road, the technical data of the automobiles, the height of their centre of gravity, etc., are inserted or are evaluated by the program itself. 


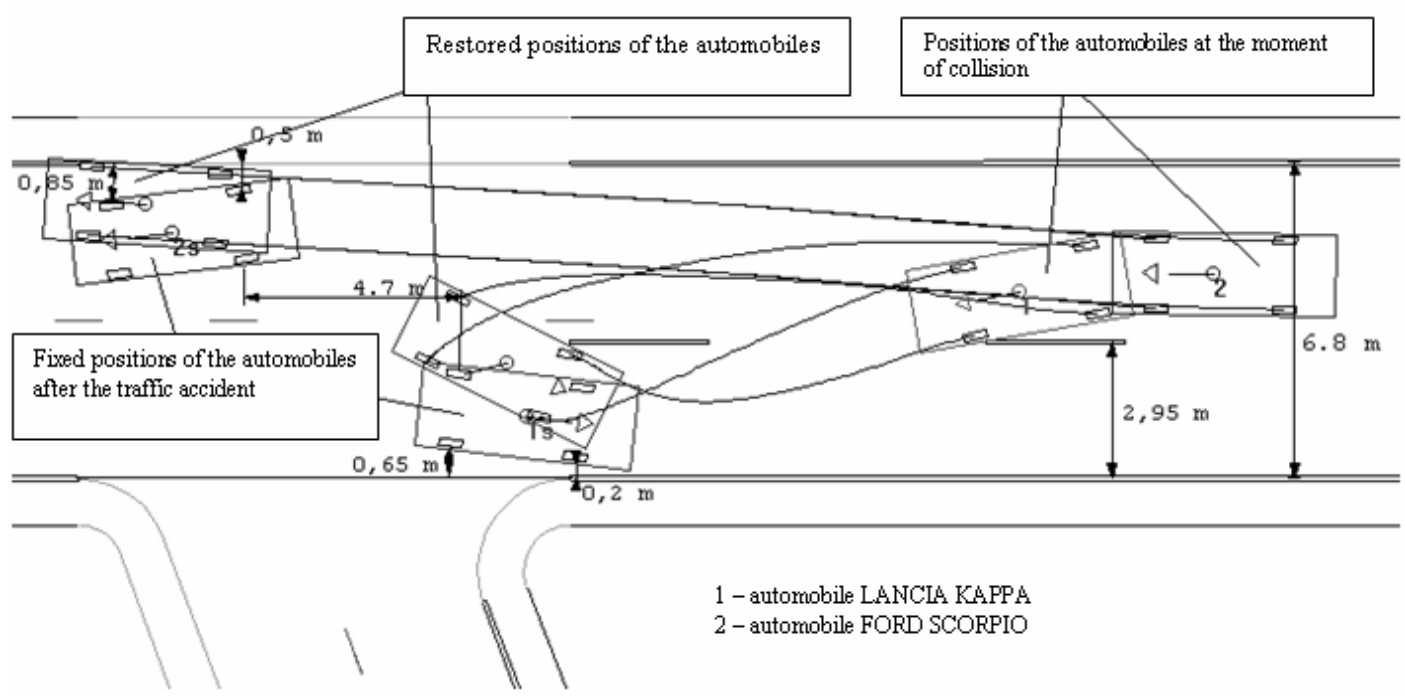

Fig 3. Collision of the automobiles LANCIA KAPPA and FORD SCORPIO

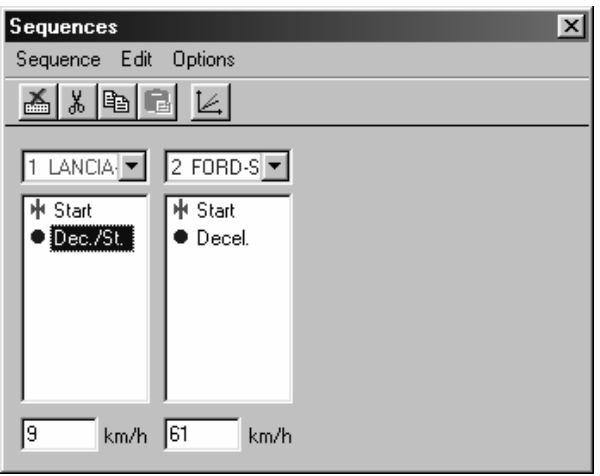

Fig 4. Insertion of the parameters of movement of the automobiles

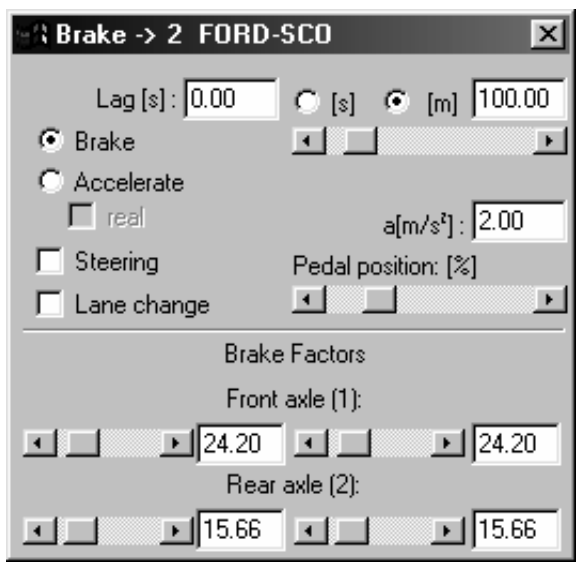

Fig 5. Insertion of the braking parameters of the automobile FORD SCORPIO

After having carried out modelling of collision of the automobiles, it was ascertained that, with taking into consideration a certain speed of the auto- mobiles (the speed of the automobile LANCIA KAPPA $-9 \mathrm{~km} / \mathrm{h}$ and the speed of the automobile FORD SCORPIO - $61 \mathrm{~km} / \mathrm{h}$ ), such traffic accident was possible, i.e. after such collision of the automobiles the automobiles may be shifted to the position, which is close to their position, which was fixed after the traffic accident (Fig 3).

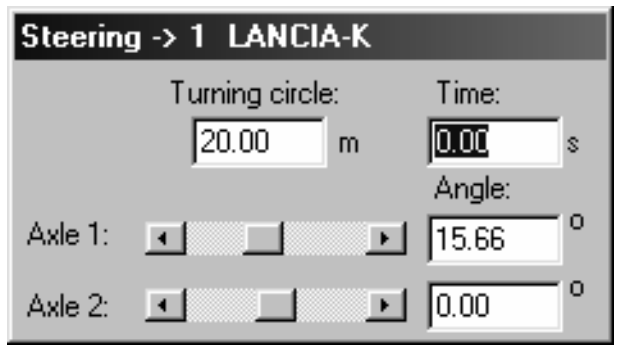

Fig 6. Insertion of the parameters of turning of the automobile LANCIA KAPPA

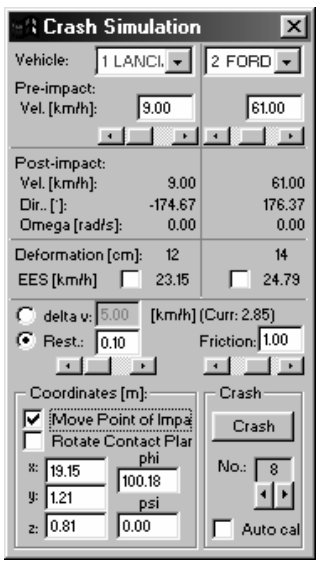

Fig 7. The parameters of collision of the automobiles 


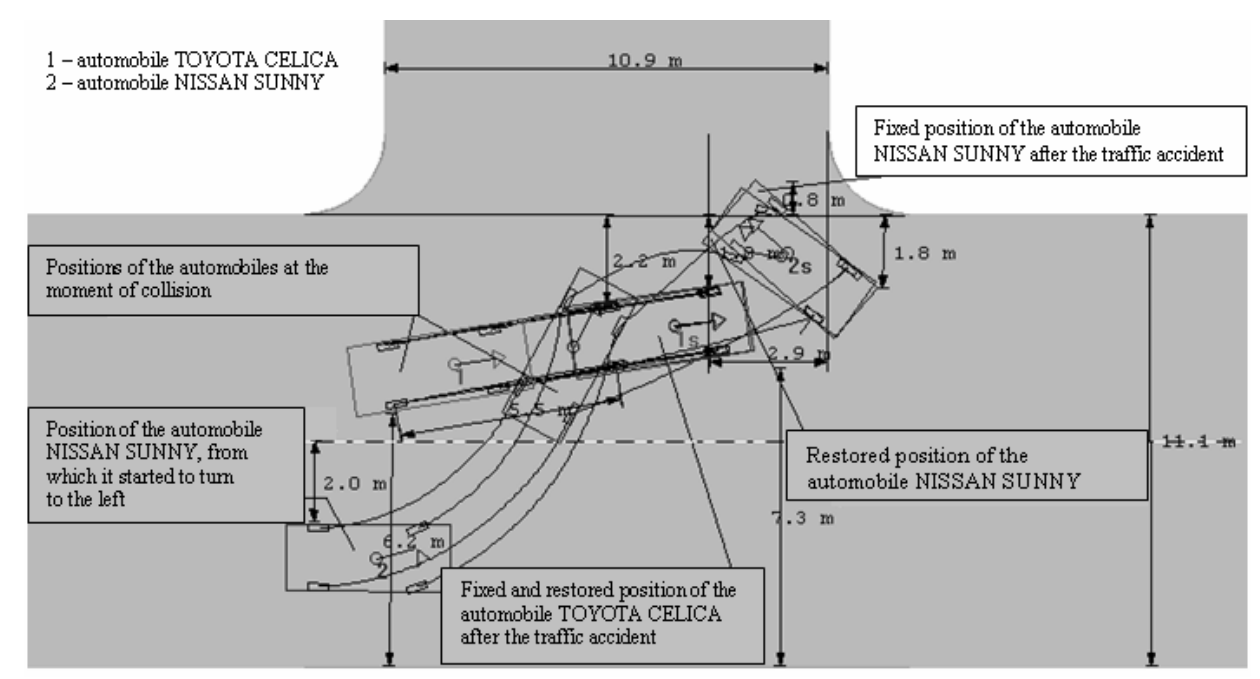

Fig 8. Collision of the automobiles TOYOTA CELICA and NISSAN SUNNY

Fig 8 reflects the modelled collision of the automobiles TOYOTA CELICA and NISSAN SUNNY. After having carried out the computer modelling, it was ascertained that the speed of movement of the automobiles prior to the traffic accident was as follows: the speed of the automobile TOYOTA CELICA $-50 \mathrm{~km} / \mathrm{h}$, the speed of the automobile NISSAN SUNNY $-16 \mathrm{~km} / \mathrm{h}$. In this case it was also necessary to ascertain, if the driver of the automobile NISSAN SUNNY, prior to making a turn to the left, had reformed and kept to the very left edge of the part of the carriage-way, meant for driving in his direction. As the position of the automobiles was ascertained according to the damages caused to the automobiles, wishing to ascertain from which position the automobile NISSAN SUNNY could start turning to the left, it was ascertained that at the moment of collision the automobile was shifted back from its position within the radius of its turn, which was close to the minimal radius of its turn, with taking into consideration the speed of this automobile prior to occurrence of the traffic accident. Thus, it was ascertained that the driver of the automobile NISSAN SUNNY was turning to the left not from the very edge of the left position. Fig 9 reflects the space view of the course of this traffic accident.

Seeking to achieve the reliable results of modelling of the course of traffic accidents, it is very important that the modelling is done by a qualified expert, who has the appropriate qualification, enabling him to insert the necessary parameters, and who has sufficient skills in working with the computer modelling program. Only in this case the results of modelling can be reliable and can be used in the experts' examination of traffic accidents because the results of modelling depend upon the inserted parameters very much.

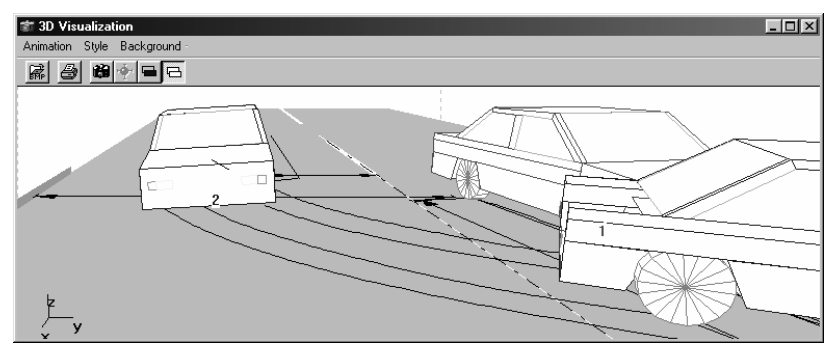

Fig 9. The space view of the course of the traffic accident

\section{Conclusions}

1. The graphic analytical modelling of movement of vehicles requires many efforts and much time, especially while investigating collisions of the automobiles, when it is necessary to evaluate very many various parameters and it is wished to consider several possible variants. This job can be simplified with the help of the computer modelling by applying special computer programs, meant for this purpose, such as the program PC CRASH.

2. The submitted examples of modelling of collisions of the automobiles prove the possibilities and advantages of the computer modelling. One of the main advantages of the computer program PC CRASH is the possibility to optimize the course of the traffic accident according to the certain selected parameters. Thus, the program itself optimizes these chosen parameters to such an extent, so that the automobiles stop in the position, which is close to the position, in which they were fixed after the traffic accident. However, seeking to obtain as more precise result as possible, it is necessary to insert as many 
available parameters as possible, whereas the parameters, the values of which may fluctuate within the certain limit, should be optimized.

3. Seeking to achieve the reliable results of modelling of the course of traffic accidents, it is very important that the modelling is done by a qualified expert, who has the appropriate qualification, enabling him to insert the necessary parameters, and who has sufficient skills in working with the computer modelling program. Only in this case the results of modelling can be reliable and can be used in the experts' examination of traffic accidents because the results of modelling depend upon the inserted parameters very much.

\section{References}

1. Borovskij, B. E. Traffic safety of automobile transport (Безопасность движения автомобильного транспорта). Leningrad, 1984. 304 p. (in Russian).

2. Danner, M.; Halm, J. Technical analysis of road accidents (Technische Analyse von Verkehrsunfällen). Eurotax (International) AG CH-8808 Pfäffikon, 1994. 570 p. (in German).

3. Ilarionov, V. A. Examination of road traffic accidents (Экспертиза дорожно-транспортных происшествий). Moscow: Transport, 1989. 254 p. (in Russian).

4. Lukoševičiene, O. The accident analysis and simulation. Monograph (Autoịvykių analizė ir modeliavimas. Monografija). Vilnius: Technika, 2001. 244 p. (in Lithuanian).

5. PC-CRASH. A Simulation program for vehicle accidents. Dr. Steffan Datentechnik, 1996. 202 p.

6. Wach, W. PC CRASH. A Simulation program for Vehicle Accidents (PC CRASH. Program do symulacji wypadków drogowych. Poradnik užytkownika). Cracow: Wydawnictwo IES, 2001. 353 p. (in Polish).

7. Ahlgrimm, J.; Grandel, J. Evaluation of traffic accident to cars with antilock brake system (ABS) (Verkehrsunfallaufnahme bei Fahrzeugen mit Anti-BlockierSystem (ABS)). Verkehrsunfall und Fahrzeugtechnik, No 3, 1997, p. 67-74 (in German).

8. Bogdevičius, M.; Prentkovskis, O.; Vladimirov, O. Engineering solutions of traffic safety problems of road transport. Transport, 2004, Vol XIX, No 1, p. 43-50.

9. Lanzendoerfer, J.; Szczepaniak, C.; Szosland, A. Theory of automobile move (Teoria ruchu samochodu). Łódź: Wydawnictwo politechniki łódzkiej, 1988. 340 p. (in Polish).

10. Sokolovskij, E. Investigation of interaction of the wheel with the road and its elements in the context of examination of traffic accidents. Doctoral Dissertation (Rato sąveikos su keliu ir jo elementais tyrimai eismo ivvkių ekspertizės kontekste. Daktaro disertacija). Vilnius: VGTU, 2004. 147 p. (in Lithuanian). 